\title{
Channel sounding and indoor radio channel characteristics in the W-band
}

\author{
Maria-Teresa Martinez-Ingles ${ }^{4}$, Davy P. Gaillot ${ }^{2}$, Juan Pascual-Garcia' ${ }^{1}$, Jose-Maria Molina-Garcia-Pardo ${ }^{*}$, \\ José-Víctor Rodríguez ${ }^{1}$, Lorenzo Rubio ${ }^{3}$ and Leandro Juan-Llácer ${ }^{1}$
}

\begin{abstract}
This work presents directional radio channel measurements in the W-band using a commercial versatile channel sounder based on a vector network analyzer (VNA), capable of measuring scattering parameters from 75 to $500 \mathrm{GHz}$ with frequency converters. The commercial setup has been modified by increasing the distance for one of the converters using precision coaxial cables and avoiding the use of amplifiers. Firstly, initial distance-dependent single-input singleoutput (SISO) measurements of indoor radio channels are presented to assess the validity of the setup in the $75-110 \mathrm{GHz}$ frequency band with highly directive horn antennas. Then, single-input multiple-output (SIMO) radio channels were measured at $94 \mathrm{GHz}$ using one directional and one omnidirectional antenna mounted on two positioners. Initial channel characterization is presented comprising root mean square (rms) delay spread, rms angular spread, K-factor, and path loss in an indoor environment at $94 \mathrm{GHz}$.
\end{abstract}

\section{Introduction}

The UE Horizon 2020 considers the extension of wireless communication systems to frequencies above $60 \mathrm{GHz}$ as one of its priorities (http://ec.europa.eu/programmes/horizon2020/); specifically, it aims to fill the gap between the millimeter and the terahertz spectrum. This frequency range between 60 and $300 \mathrm{GHz}$ is not limited to communications but also finds application in remote sensing, security, and industrial measurement. The use of this band has been proposed for high-speed data links, automotive radar, radar imaging, security screening, substance identification, and non-destructive testing among others $[1-3]$.

In terms of the W-band $(75-110 \mathrm{GHz})$, most of the studies found in the literature date from the 1990s, and all of them are narrowband. In [4], propagation in the evaporation duct at $94 \mathrm{GHz}$ is studied, in [5] a computational study at 94 and $140 \mathrm{GHz}$ for oblate spheroidal and spherical raindrops is performed, and in [6], some propagation studies with rain are performed at $94 \mathrm{GHz}$. The first indoor propagation (narrowband path loss) measurements at $94 \mathrm{GHz}$ are found in [7] and wideband in [8]. In [9], wideband measurements over the

\footnotetext{
* Correspondence: josemaria.molina@upct.es

1 Departamento Tecnologías de la Información y las Comunicaciones,

Universidad Politécnica de Cartagena, Cartagena, Spain

Full list of author information is available at the end of the article
}

full W-band are performed but limited to short distances. In addition, body area networks (BANs) have shown interest in these frequencies [10]. Therefore, as far as the authors are concerned, there is little analysis on indoor wideband measurements in the W-band.

In this work, a commercial channel sounder setup designed for sounding a radio propagation channel beyond $67 \mathrm{GHz}$, which is the limit of coaxial wired typical vector network analyzer (VNA) (few models reach $100 \mathrm{GHz}$ ), to up to $500 \mathrm{GHz}$ is described. A link budget of the coaxial cables connection to the converter is presented, which enable wireless measurements from 50 to $500 \mathrm{GHz}$ (depending on the converter model). In this work, we focus on the W-band frequency range.

First, single-input single-output (SISO) in the 75$110 \mathrm{GHz}$ are presented by using two horn antennas used for the SISO measurements in order to validate the developed measurement setup. Later, directional measurements within $3 \mathrm{GHz}$ around $94 \mathrm{GHz}$ are presented in an indoor environment. However, channel sounding for radio characterization is typically performed with omnidirectional antennas. At these frequencies, the required dynamic range is higher than at lower bands, i.e., a path loss of $72.4 \mathrm{~dB}$ is theoretically obtained at $1 \mathrm{~m}$ for $100 \mathrm{GHz}$. To alleviate this issue, one omnidirectional

\section{Springer}

(C) 2016 Martinez-Ingles et al. Open Access This article is distributed under the terms of the Creative Commons Attribution 4.0 International License (http://creativecommons.org/licenses/by/4.0/), which permits unrestricted use, distribution, and reproduction in any medium, provided you give appropriate credit to the original author(s) and the source, provide a link to the Creative Commons license, and indicate if changes were made. 
antenna is used at one side whereas a rotary system with a high directivity horn antenna is used at the other side to construct an omni-like radiation pattern with a higher dynamic range. This approach was used with $70 \mathrm{GHz}$ in [11]. Preliminary results such as root mean square (rms) delay spread, rms angular spread, path loss, and K-factor are presented and discussed.

This paper is organized as follows: Section II focuses on the description of the channel sounder based on a commercial VNA, Section III presents wideband measurements in the W-band using horn antennas to assess the validity of the setup, Section IV focuses on the channel characteristics at the $94 \mathrm{GHz}$ frequency for an indoor environment, and Section $\mathrm{V}$ concludes the work.

\section{Channel sounder}

The millimeter-wave channel sounder setup is described in Fig. 1. It is based on a commercial vector network analyzer (VNA), the R\&S ZVA 67, and up-converters (http:// www.rohde-schwarz.es/product/ZVAZ.html). In this work, the R\&S ZVA-Z110E converter (W-band WR-10, 75 to $110 \mathrm{GHz}$ ) was used for both the transmitting and receiving unit. The commercial setup is limited to the separation of the converters up to $1 \mathrm{~m}$. In order to communicate between the converter and the VNA, four signals come out from the VNA to each converter, and they are used to measure different $\mathrm{mmW}$ frequency bands (note that each converter slightly differs in these frequencies):
1. Source input (RF, magenta): 12.5 to $18.33 \mathrm{GHz}$. Input power in the converter: 4 to $10 \mathrm{dBm}$.

2. Local oscillator input (LO, blue) IN: 9.34 to $13.715 \mathrm{GHz}$. Input power in the converter: 5 to $10 \mathrm{dBm}$

3. Measurement output (MEAS, orange): 10 to $300 \mathrm{MHz}$.

4. Reference output (REF, green): 10 to $300 \mathrm{MHz}$.

The output power of the VNA is typically greater than $15 \mathrm{dBm}$ such that a $10 \mathrm{~dB}$ margin was used for the cables or amplifiers to separate the converter from the VNA (magenta, blue, green, and orange in Fig. 1). This point is the extension from the application note from the manufacturer.

In order to take measurements in this frequency band, it was decided not to use amplifiers in order to simplify the setup and because the dynamic range was enough for the distances considered in the study. Two RG-58 cables with SMA connector were used for REF and MEAS, and two 8-m TRUCore300 cables were used for RF and LO. These cables had an insertion loss of $7.8 \mathrm{~dB}$ at $18 \mathrm{GHz}$. Figure 2 presents the VNA setup for using the converters.

The system was THROUGH calibrated (Fig. 3), being included the delay and gain of the antennas in the measurements. The measured dynamic range for an intermediate frequency (IF) of $100 \mathrm{~Hz}$ was $97 \mathrm{~dB}$. The channel transfer functions were thus measured by the $\mathrm{S}_{21}$-scattering parameter in the frequency domain.

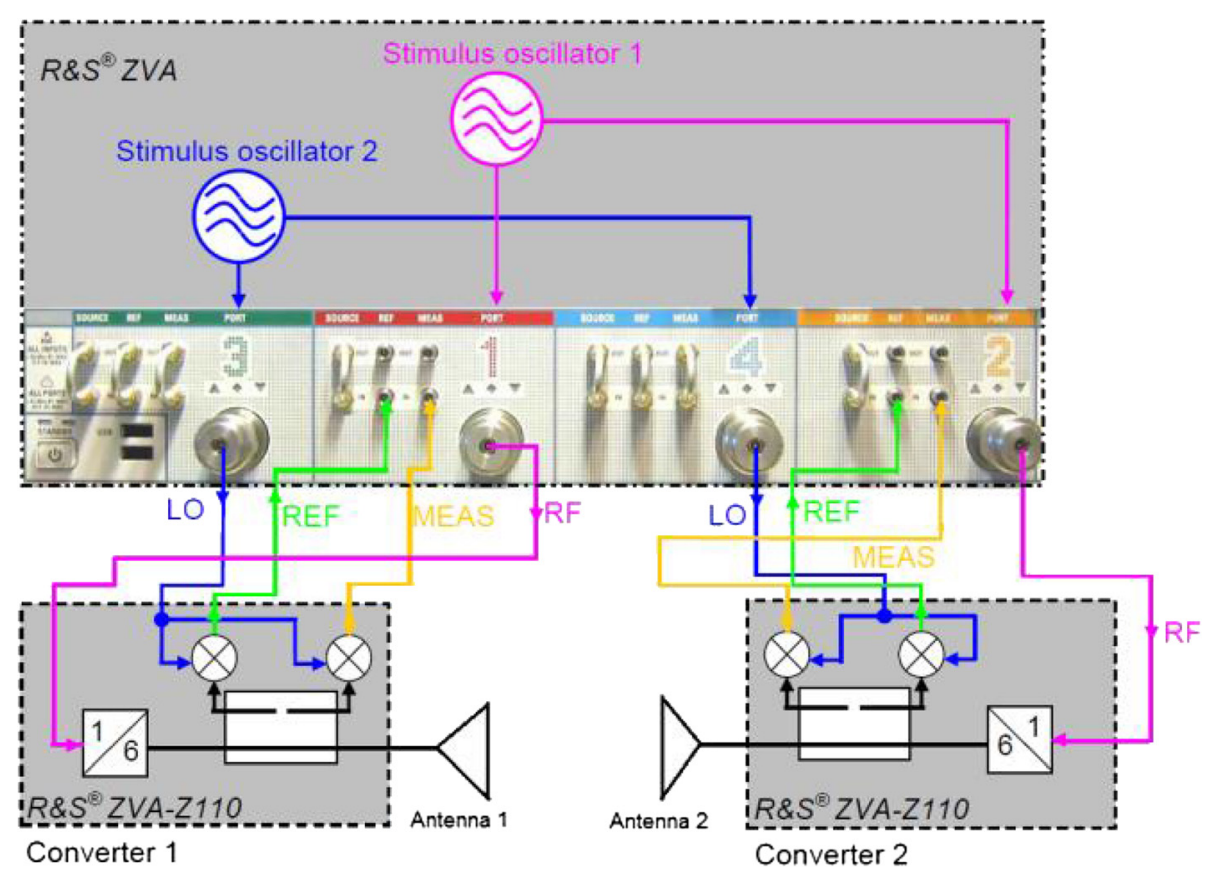

Fig. 1 Millimeter-wave channel sounder setup 


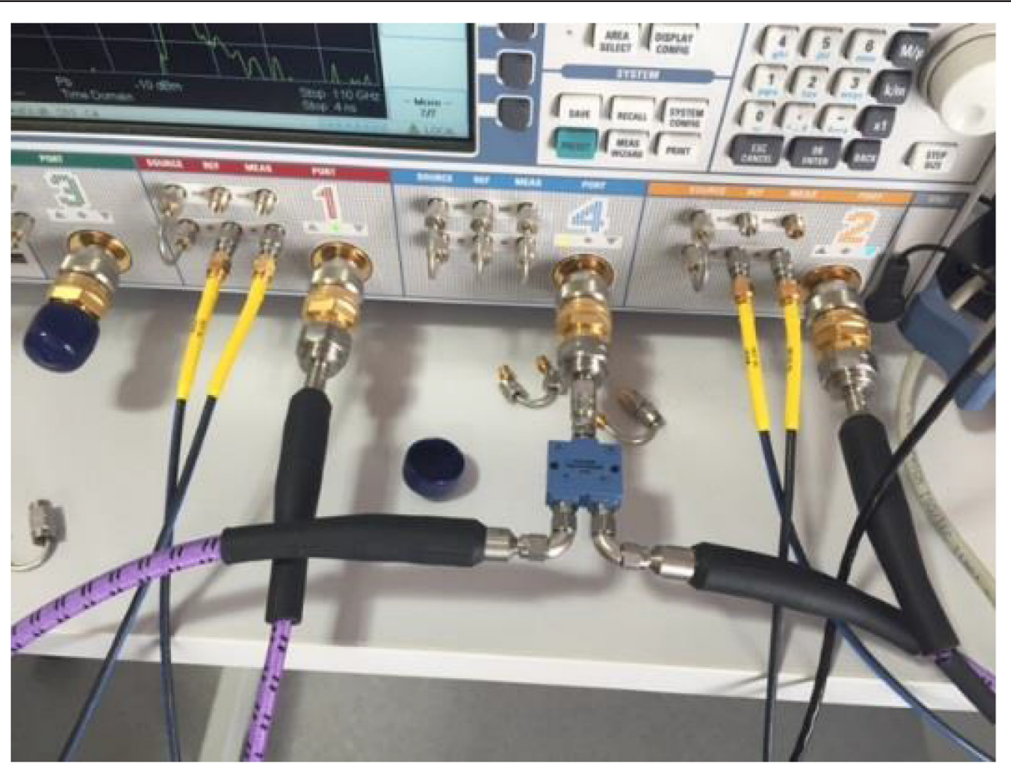

Fig. 2 Photo of cables connected to the VNA

\section{Channel sounder validation, $75-110 \mathrm{GHz}$ SISO measurements}

In this section, we will validate the use of the channel sounder with SISO measurements. Two horn antennas manufactured by Flann Microwave (Model 27240-20 (http://www.flann.com/)) were connected to the channel sounder described in Section II. The antennas operate in the $73.8-112 \mathrm{GHz}$ range with gain values varying between 18 and $21.5 \mathrm{dBi}$, as shown in Fig. 4. The VNA was configured to measure the $\mathrm{S}_{21}$-scattering parameter from 75 to $110 \mathrm{GHz}$, i.e., $35 \mathrm{GHz}$ of SPAN and a central frequency equal to $92.5 \mathrm{GHz}$, with $N_{\mathrm{f}}=2048$ frequency points and 50 times averaged. A picture of the setup can be seen in Fig. 5 .

For these first measurements, near line-of-sight (LOS) channel realizations were measured for distance values ranging between 10 and $70 \mathrm{~cm}$. Figure 6 shows the measured wideband path loss (PL) at each position taking into account the frequency gain of the antennas and the frequency characteristics of free-space propagation. The PL has been calculated as an extension of the Friis formula for the case of ultra wideband as described in [12]. Thus, the PL is derived as the ratio

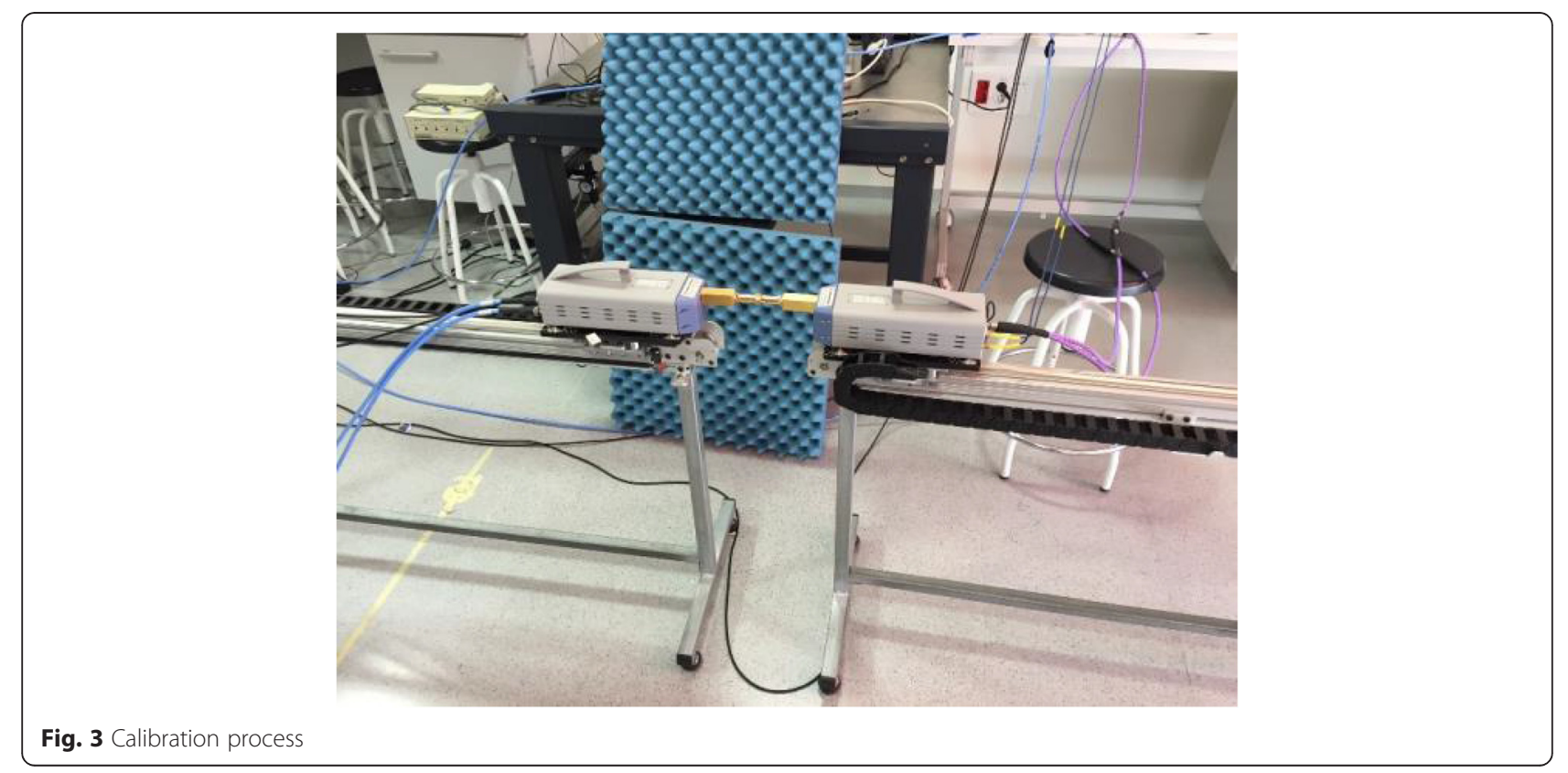




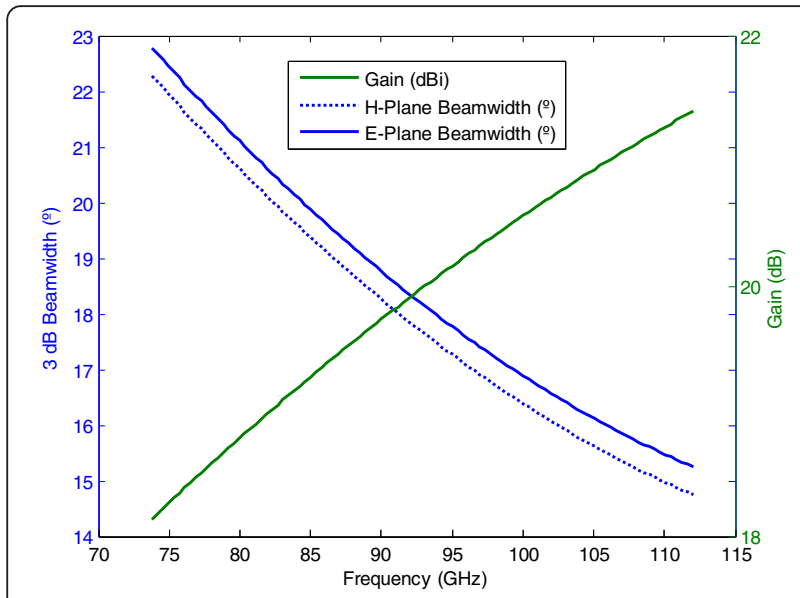

Fig. 4 Horn antenna specifications in the W-band

between the transmit energy and the energy of the received signal over the $35 \mathrm{GHz}$ bandwidth. It is assumed that there are no polarization losses between the antennas being both vertical polarized. The PL can be derived from the antenna gain $(g(f))$, and $S_{21}(f)$ the scattering parameter as:

$$
\operatorname{PL}(\mathrm{dB})=-10 \log _{10}\left(\int_{f_{\min }}^{f_{\max }} \frac{1}{g^{2}(f)}\left|S_{21}(f)\right|^{2} d f\right)
$$

where $f_{\min }$ and $f_{\max }$ are 75 and $110 \mathrm{GHz}$, respectively. In discrete form, (1) can be rewritten as

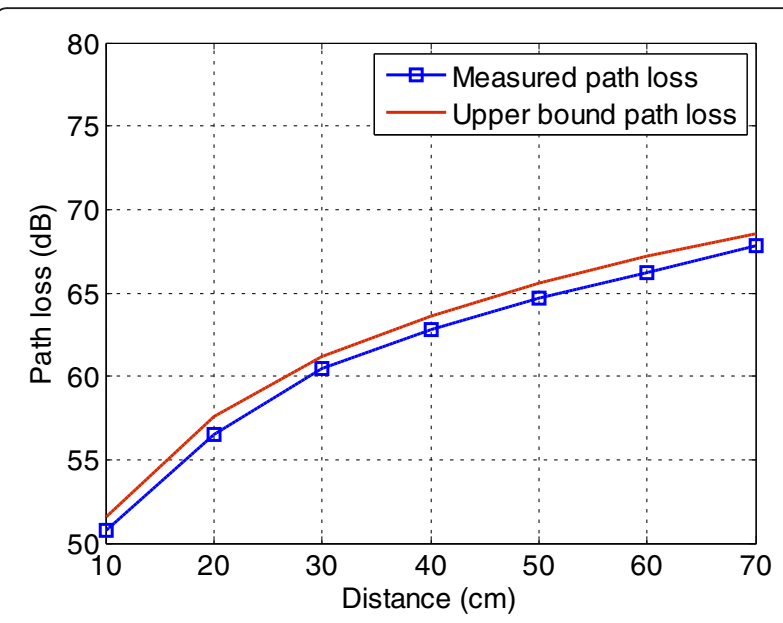

Fig. 6 Measured and the upper bound path loss in the W-band

$$
\mathrm{PL}(\mathrm{dB})=-10 \log _{10}\left(\frac{1}{N_{f}} \sum_{n=0}^{N_{f}-1} \frac{\left|S_{21}\left(f_{\min }+n \Delta f\right)\right|^{2}}{g^{2}\left(f_{\min }+n \Delta f\right)}\right)
$$

where the frequency resolution used in the measurements is given by:

$$
\Delta f=\frac{f_{\max }-f_{\min }}{N_{f}-1} .
$$

As a comparison, we have also plotted in Fig. 6 the upper bound of the path loss, $\mathrm{PL}_{\mathrm{UB}}$, derived when ideal

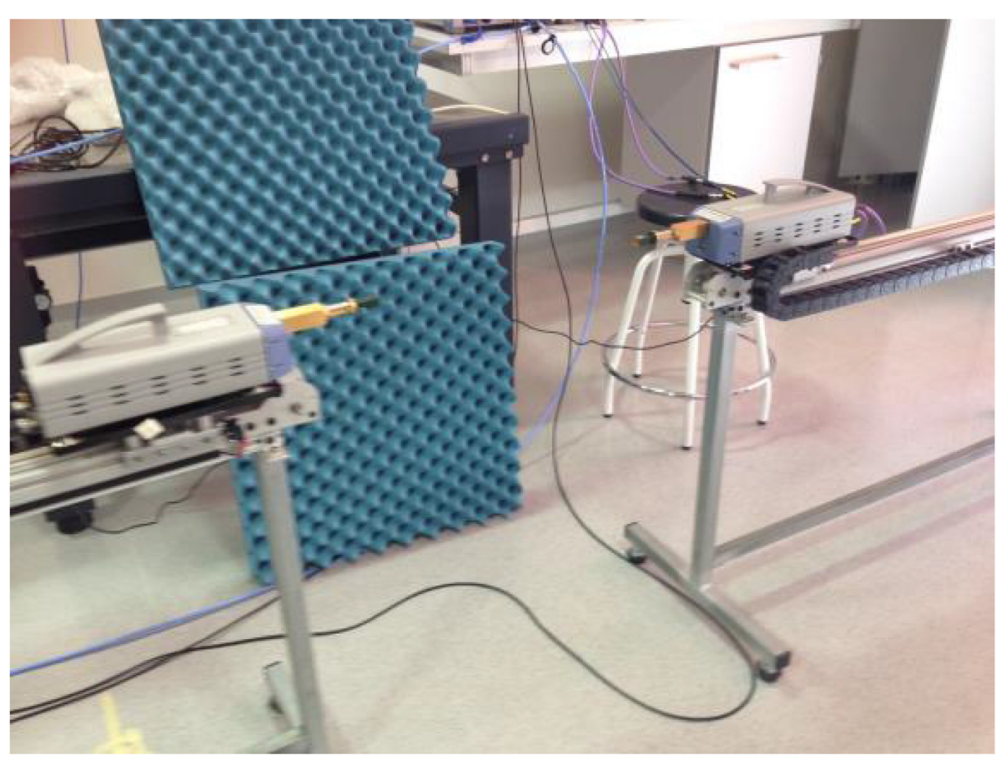

Fig. 5 Picture of one of the first trials 


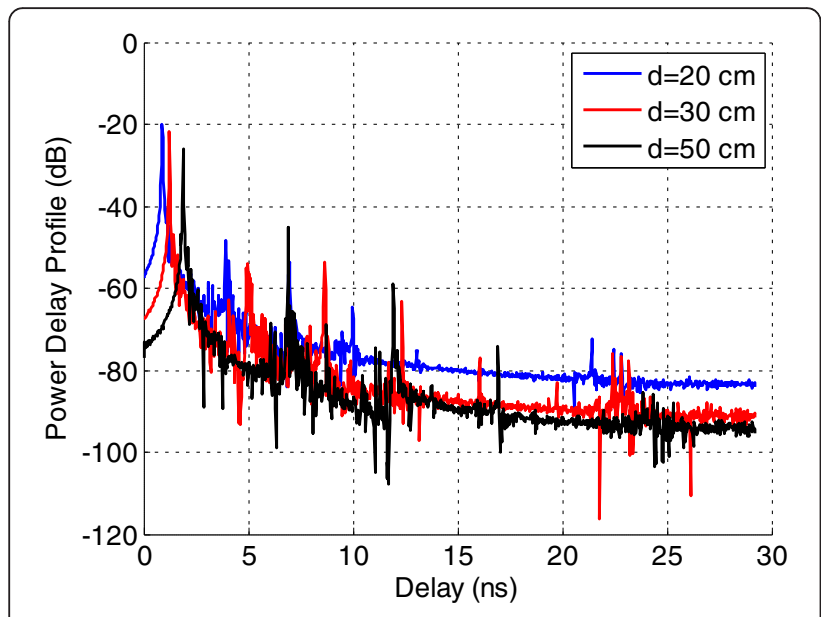

Fig. 7 PDP for $T x-R x$ distances of 20,30 , and $50 \mathrm{~cm}$

isotropic antennas are used for a uniform transmit spectrum given by [12]:

$$
\mathrm{PL}_{\mathrm{UB}}(\mathrm{dB})=-10 \log _{10}\left(\frac{c^{2}}{(4 \pi d)^{2} f_{\text {min }} f_{\text {max }}}\right)
$$

where $c$ is the velocity of the light and $d$ is the Tx-Rx separation distance. Notice that when $f=f_{\min }=f_{\max },(4)$ is the free-space path loss for a narrowband transmission.

An average $0.84 \mathrm{~dB}$ error was measured between both curves, probably due to slight variations between the real gain and the manufacturer datasheet. The maximum dimension of the antenna was $26 \mathrm{~mm}$, and at the W-band meant a far zone distance of $2(0.026)^{2} / \lambda_{\min } \approx 49 \mathrm{~cm}$, being $\lambda_{\text {min }}=c / f_{\max }$. Even if between 10 and $50 \mathrm{~cm}$, we do not fulfill the far zone, the ultra wideband formula predicts the path loss accurately.
The time-delay responses and power delay profile (PDP) can be obtained from the complex channel transfer functions via the classical inverse Fourier transform. Figure 7 shows the PDPs for three selected distances (20, 30, and $50 \mathrm{~cm})$. For these distances, the RMS delay spread computed with a $30-\mathrm{dB}$ threshold is $0.12,0.24$, and 0.49 ns, respectively. From these curves, it is also shown that strong SMCs (specular multipath components) lie between 5 and 25 ns and that dense multipath components (DMCs) do not contribute much to the received power. This is mainly due to reflections of close objects such as the table, VNA, or the converters. The dynamic range is shown to be sufficient even by using a $100-\mathrm{kHz}$ intermediate frequency.

\section{$4 \mathrm{GHz}$ SIMO measurements}

In this section, indoor channel characteristics are measured by performing SIMO measurements, carried out with virtual Tx-UCA (Uniform Circular Array) and virtual Rx-URA (Uniform Rectangular Array) systems. The VNA is configured with 1024 frequency points and $10 \mathrm{~Hz}$ IF.

For the transmitter, the virtual Tx-UCA uses the same horn antenna as in the previous section. For the virtual Rx-URA, an omnidirectional antenna manufactured by Mi-Wave (WR-10) was selected. This antenna operates at $94 \mathrm{GHz}$ with a $3 \mathrm{GHz}$ bandwidth, $2 \mathrm{~dB}$ gain and typical nominal VSWR of 1.5:1 [http://www.miwv.com/]. Vertical polarization has been used for all cases.

The Rx position was fixed whereas the Tx was moved around four different positions in a room. A map of the indoor scenario can be found in Fig. 8.

Figure 9 presents a general photo of the scenario from the $\mathrm{Tx}$ antenna. The $\mathrm{Tx}$ and $\mathrm{Rx}$ antennas were

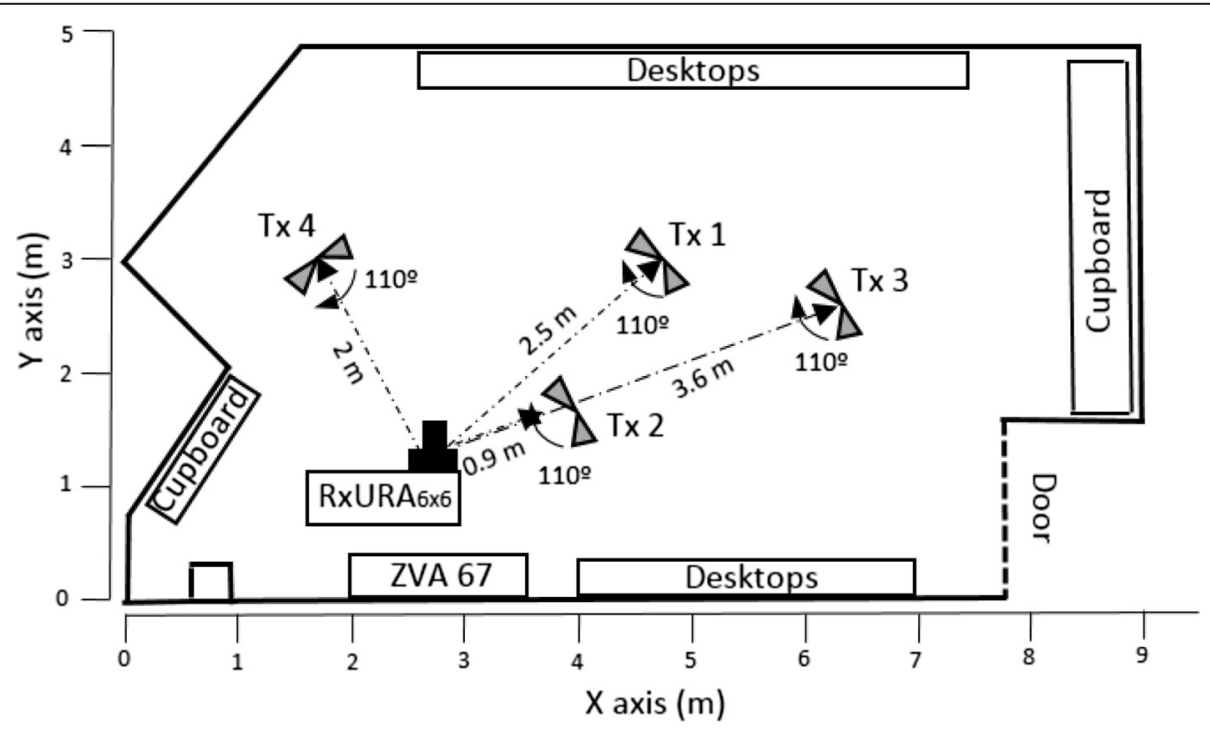

Fig. 8 Map of the measured room 


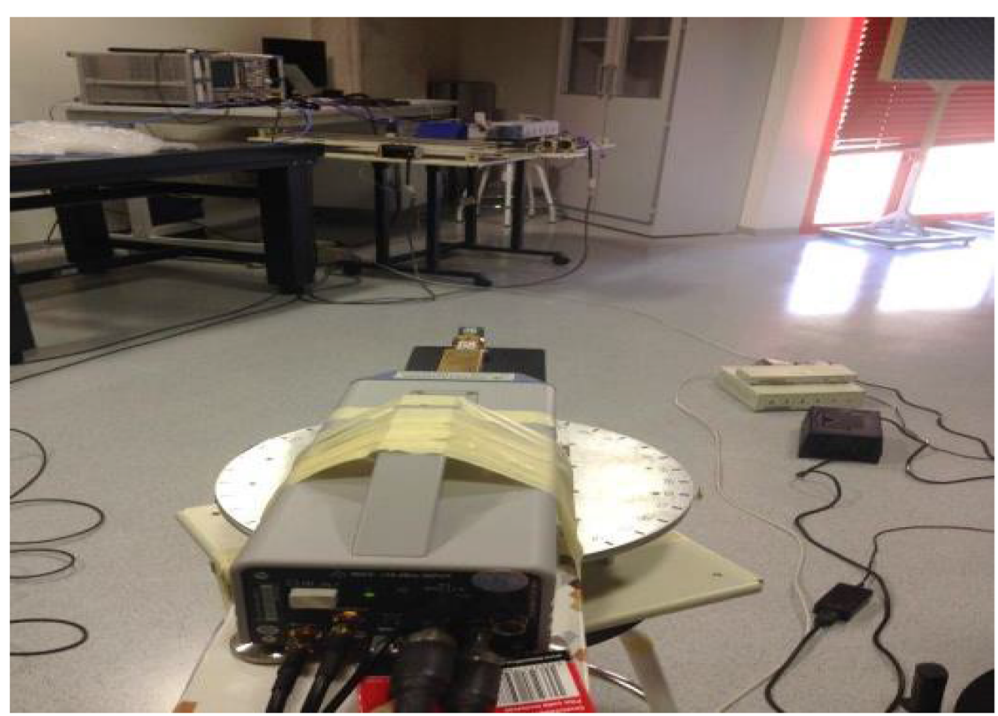

Fig. 9 General view of the scenario for $94 \mathrm{GHz}$ measurements

operated with Arricks Robotics positioners (http:// www.arrickrobotics.com/). The Tx-Rx distances were 2.552, 0.987, 3.692, and $2.092 \mathrm{~m}$ for Tx1, Tx2, Tx3, and $\mathrm{Tx} 4$, respectively.

For the virtual $\mathrm{Tx}-\mathrm{UCA}$, a $110^{\circ}$ range was measured with a $10^{\circ}$ step while the phase center of the antenna was kept fixed for all orientations. In all cases, and for comparison purposes, the horn antenna coordinate system was aligned such that the maximum received gain could be obtained for $55^{\circ}$ angles between the UCA and URA (see Fig. 8), i.e., the mean angle is always facing the $\mathrm{Rx}$, and it will be plotted in such a way for all results. The rotation of the UCA is clockwise. For the virtual URA, measurements were performed over a $6 \times 6$ uniform rectangular grid with $1.4 \mathrm{~mm}$ spacing along $\mathrm{X}$ and $\mathrm{Y}$, corresponding to $0.4 \lambda$ at $94 \mathrm{GHz}$. Table 1 summarizes the coordinates of each Tx and the Rx.

The relative received power, computed as the averaged received power in the frequency domain (over the $3 \mathrm{GHz}$ bandwidth), is shown in Fig. 10 for all considered positions and horn antenna angles. We can see how maximum values of the received power are obtained between $50^{\circ}$ and $60^{\circ}$, since the UCA was aligned at $55^{\circ}$ for all cases. This received power can be compared with the

Table 1 Coordinates of $T x$ and $R x$

\begin{tabular}{lll}
\hline & $X(m)$ & $Y(m)$ \\
\hline$R \times$ & 2.75 & 1.2 \\
$T \times 1$ & 4.79 & 2.97 \\
$T \times 2$ & 3.95 & 1.7 \\
$T \times 3$ & 6.3 & 2.63 \\
$T \times 4$ & 1.81 & 2.98 \\
\hline
\end{tabular}

power computed from the free-space path loss with the optimum orientation (including $18.5 \mathrm{~dB}$ of the horn antenna and $2 \mathrm{~dB}$ for the omni antenna). Indeed, at 94 $\mathrm{GHz}$ with a $3-\mathrm{GHz}$ bandwidth, the transmission is narrowband and the Friis formula converges to the upper bound for wideband free-space path loss. The received power for $\mathrm{Tx} 1, \mathrm{Tx} 2$, Tx3, and $\mathrm{T} 4$ are 61.4 (59.5), 57.7 (51.3), 64.5 (62.7), and 54.8 (57.8) dB, respectively, being the simulated received power inside the parenthesis. The difference was attributed to an additional complexity in both delay and angular domain (i.e., presence of multipath components). Also, another reason is attributed to the mismatch between the $55^{\circ}$ alignment and the measured angles of $50^{\circ}$ and $60^{\circ}$ due to the selected $10^{\circ}$ angular step.

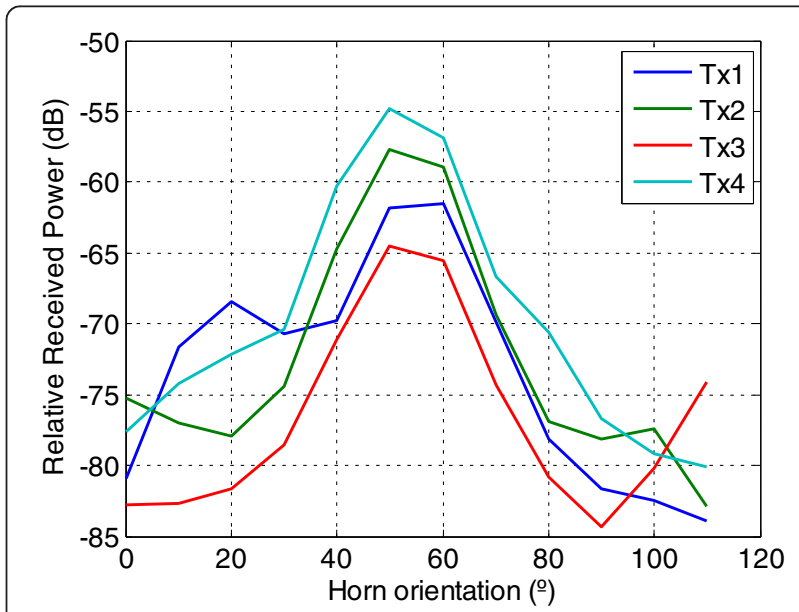

Fig. 10 Relative received power (in $\mathrm{dB}$ ) as a function of the UCA horn antenna angle (in ${ }^{\circ}$ ) 


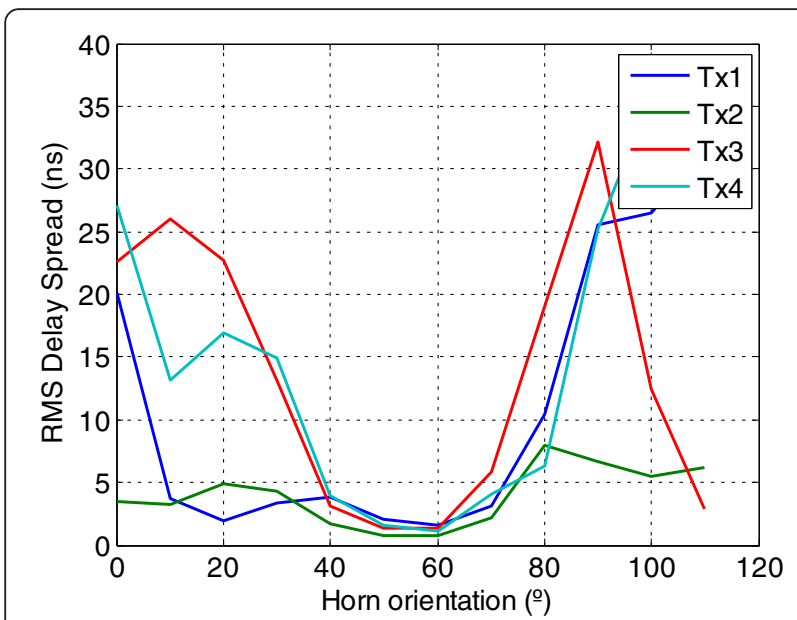

Fig. 11 RMS delay spread (in ns) as a function of the UCA horn antenna angle (in ${ }^{\circ}$ )

The rms delay spread was also computed with a $30-\mathrm{dB}$ threshold (Fig. 11). A minimum in the rms values was clearly observed when the horn antenna axis was facing the URA with values of $1.58,0.74,1.3$, and $1.61 \mathrm{~ns}$ for position 1 to 4 , respectively. However, when the axes were not aligned, values up to 30 ns were obtained because of multiple reflections in the scenario.

In addition, the maximum-likelihood estimation (MLE) parameters of the Ricean distribution were computed from the frequency domain data [13]. Figure 12 shows the K-factor of the best-fitting distribution for all Tx positions. As observed in Fig. 11, large values of $\mathrm{K}$ were measured when the horn antenna faced the URA with maximum values of $14.3,11.12,6.9$, and $11.4 \mathrm{~dB}$ for position 1 to 4 , respectively. On the other hand, Rayleigh distributions were obtained for the side angles.

All previous results strongly indicate that the complexity of the measured radio channels depends on the horn

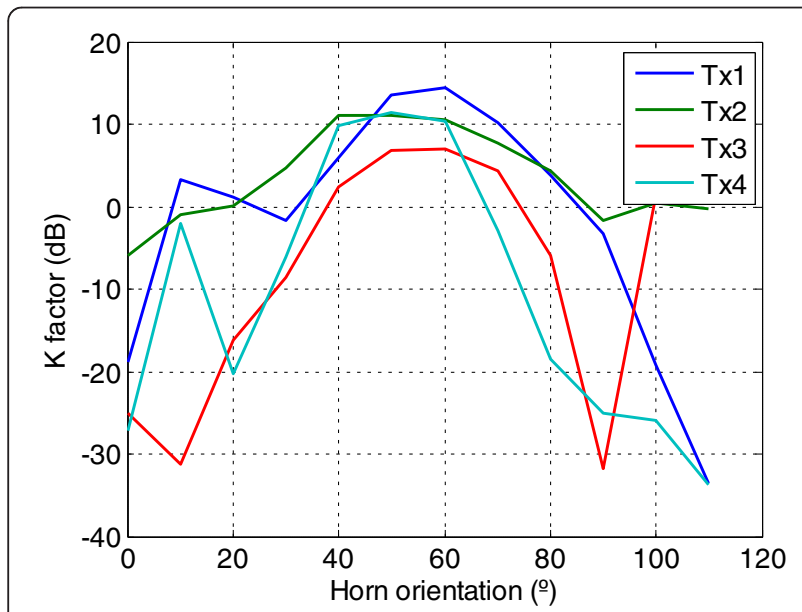

Fig. 12 K-factor (in $\mathrm{dB}$ ) as a function of the UCA horn antenna angle $\left(\right.$ in $\left.^{\circ}\right)$

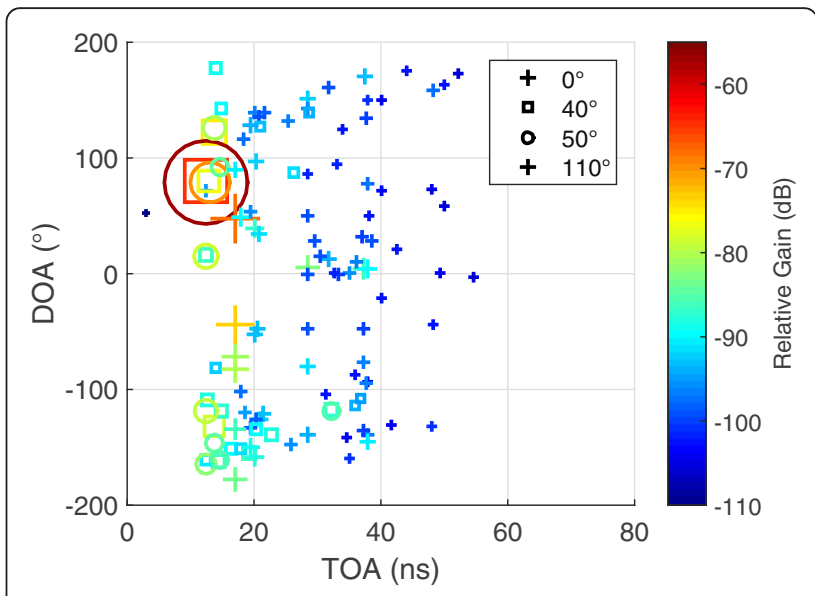

Fig. $13 \mathrm{TOA}$ (in ns) as a function of DOA (in ${ }^{\circ}$ ) estimated with RiMAX as for $\operatorname{Tx} 3$ with $0^{\circ}, 40^{\circ}, 50^{\circ}$, and $110^{\circ}$ horn antenna angles

antenna angle with respect to the Rx. To analyze this effect, high-resolution MLE RiMAX [14] was subsequently applied to the measured SIMO radio channels to extract the SMCs for each position and horn antenna angle. For instance, the time-of-arrival (TOA), direction-of-arrival (DOA), and complex gain were jointly estimated for each path, as well as the DMCs.

As an example, Fig. 13 presents the SMCs estimation results for $\mathrm{Tx} 3$ with $0^{\circ}, 40^{\circ}, 50^{\circ}$, and $110^{\circ}$ horn antenna angles. The power of each SMC is proportional to the the circle radius and is also presented with a color scale. From this information, the rms angular spread was also computed with a $30-\mathrm{dB}$ threshold (Fig. 14). Again, the data show that the angular spread reaches its minimum value $\left(72.8^{\circ}, 54.1^{\circ}, 62.2^{\circ}\right.$, and $69.6^{\circ}$ for position 1 to 4 ) when the horn antenna is aligned with the URA array.

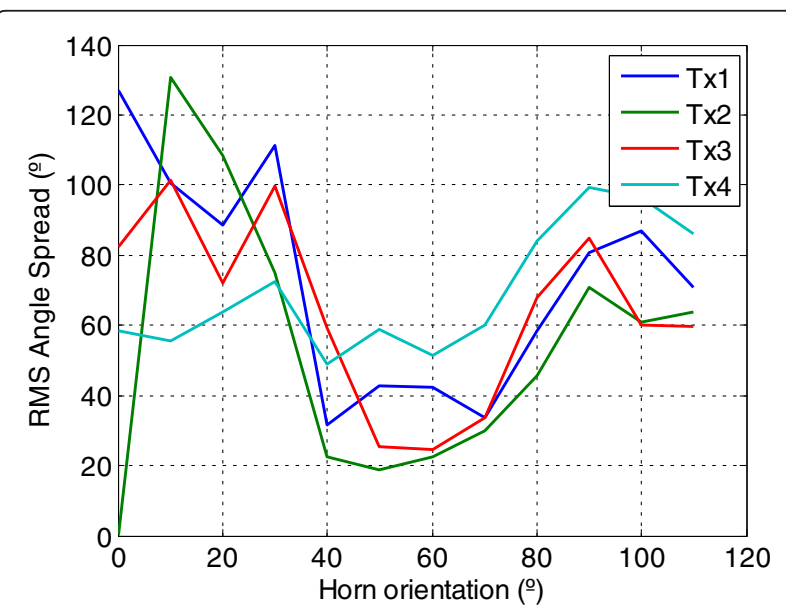

Fig. 14 RMS angular spread in terms of UCA 


\section{Conclusions}

This paper presents initial investigations of the radio channel characteristics in the W-band with a commercial VNA. The initial limited distance range of the setup has been successfully increased to much longer distances using longer precision cables between the VNA and converters. Initial SISO W-band measurements with horn antennas are shown for distance values up to $70 \mathrm{~cm}$ to validate the system. Then, SIMO measurements are presented at $94 \mathrm{GHz}$ with an omnidirectional antenna and a horn antenna mounted on a rotary system. Further work includes extensive measurement campaigns at 94 $\mathrm{GHz}$ for indoor scenarios and deeper analysis of the DMC contribution to the radio channels.

\section{Acknowledgements}

This work was supported by MINECO, Spain (TEC2013-47360-C3-2-P TEC201347360-C3-3-P) and by European FEDER funds.

\section{Author details}

1Departamento Tecnologías de la Información y las Comunicaciones, Universidad Politécnica de Cartagena, Cartagena, Spain. ${ }^{2}$ IEMN/TELICE, University of Lille 1, Villeneuve d'Ascq, France. ${ }^{3}$ Universitat Politècnica de València, Camino de Vera, Spain. ${ }^{4}$ University Center of Defense, San Javier Air Force Base, MDE-UPCT, C/Coronel López Peña, s/n, 30720, Santiago de la Ribera, Murcia, Spain.

Received: 28 July 2015 Accepted: 18 January 2016

Published online: 28 January 2016

\section{References}

1. D Zico, Ultra-wideband and $60 \mathrm{GHz}$ communications for biomedical applications. Springer. http://link.springer.com/book/10.1007\%2F978-1-46148896-5.

2. L Jofre, J Romeu, S Capdevila, J Abril, E Nova, M Alonso, The "challenging" world of Terahertz radiation and imaging. Proceedings of the 5th European Conference on Antennas and Propagation (EUCAP), 2011, pp. 3470-3475

3. M Kawase, "Non-destructive evaluation method of pharmaceutical tablet by terahertz-time-domain spectroscopy: application to sound-alike medicines", J. Infrared Millimeter Terahertz Waves, 34(9), 566-571

4. KD Anderson, $94 \mathrm{GHz}$ propagation in the evaporation duct. IEEE Trans. Antennas Propag. 38(5), 746-753 (1990)

5. K Aydin, Y-M Lure, Millimeter wave scattering and propagation in rain: a computational study at 94 and $140 \mathrm{GHz}$ for oblate spheroidal and spherical raindrops. IEEE Trans. Geosci. Remote Sens. 29(1), 593-601 (1991)

6. C Gloaguen, An experiment for propagation studies at $94 \mathrm{GHz}$. Eighth Int. Conf. Antennas Propagation 1, 406-409 (1993)

7. A Kajiwara, "Indoor propagation measurements at $94 \mathrm{GHz}$," personal, indoor and mobile radio communications, 1995. Sixth IEEE Int. Symp PIMRC'95. Wireless Merging Inf. Superhighway 3, 1026 (1995)

8. J Helminger, J Detlefsen, $\mathrm{H}$ Groll, Propagation properties of an indoor-channel at $94 \mathrm{GHz}$. Int. Conf. Microw Millimeter Wave Technol.Proc 98, 9-14 (1998)

9. R Piesiewicz, R Geise, M Jacob, J Jemai, T Kurner, "Indoor channel measurements of point-to-point ultra broadband short range links between $75 \mathrm{GHz}$ and $110 \mathrm{GHz}$ ", in International Symposium Antennas and Propagation Society, 2008, pp. 1-4

10. A Brizzi, A Pellegrini, Y Hao, "Experimental characterization of the propagation on the human torso at W band", in Radio Science Meeting (Joint with AP-S Symposium), USNC-URSI, 2013, p. 39

11. K K Haneda, J Järveläinen, A Karttunen, M Kyro, J Putkonen, Indoor short-range radio propagation measurements At 60 and $70 \mathrm{GHz}$, in EuCAP 2014, The Hague, The Netherlands, 2014, pp. 1-4
12. S Promwong, J Takada, Free space link budget estimation scheme for ultra wideband impulse radio with imperfect antennas. IEICE Electronics Express 1(7), 188-192 (2004)

13. NL Johnson, S Kotz, N Balakrishnan, Continuous univariate distributions, vol. 1 (Wiley-Interscience, Hoboken, 1993)

14. A Richter, Estimation of radio channel parameters: models and algorithms (Dr.-Ing. dissertation, TU IImenau, IImenau, Germany, 2005)

\section{Submit your manuscript to a SpringerOpen ${ }^{\circ}$ journal and benefit from:}

- Convenient online submission

- Rigorous peer review

- Immediate publication on acceptance

- Open access: articles freely available online

- High visibility within the field

- Retaining the copyright to your article

Submit your next manuscript at $>$ springeropen.com 